Bangladesh Journal of Bioethics 2014; 5(1):11-19

\title{
A REVIEW OF ETHICS IN DEVELOPING COUNTRY IN PERSPECTIVE OF DENTAL RESEARCH
}

\section{Dr. Md. Haider Ali Khan ${ }^{1}$ Shamima Parvin Lasker ${ }^{2}$}

1. Assistant Professor, Department of Dental Public Health, Dhaka Dental College, Dhaka, Bangladesh Email: haiderkhan3@hotmail.com

2. Professor and Head of Anatomy, City Dental College, Dhaka, Bangladesh

Email: splasker04@yahoo.com

ABSTRACT: The objectives of this review were to examine the ethical issues in research in developing country and perspective of dental research. In this review, we performed the systematic literature search, screening process through the web in existing published and unpublished articles and reports that related to our topics between 1990 to 2013. In the past few decades, the research and discoveries in the discipline of dentistry have increased dramatically. Recently many dental Institutes in developing country is constantly looking for opportunities to borrow, enhance, and integrate knowledge from biomedical and technological research by using modern technology. The retrieved information in this review reflect that to make any research involving human subjects ethically acceptable, a number of key features have to be considered by the researchers. Those who conduct oral health research are compelled by regulations and convention to follow established ethical standards to protect human rights. Bioethics and in ethical review of research in developing countries reveals many major gaps and have seen that there are indeed many ethical issues to be considered to clinical trials taking place in developing countries. Professional societies have a major influence in shaping the moral tone and ethical climate for research through the adoption of standards, the development of educational programs designed to reinforce those standards. Research ethics committees or institutional ethical review committees is to ensure that studies involving human research participants are designed to conform the relevant ethical standards and that the rights and welfare of participants are protected. Research ethics committees should not function under the influence of others and should ensures the favorable balance of potential benefits and risks. In developing country it is necessary to strengthen local capacity and manpower by developing innovative training models for ethics that are cost-effective and sustainable. The actions required to move ahead in this field include strengthening bioethics capacity, linking health research to community needs in a transparent and participatory process and increasing communication between scientists and ethicists in industrialized and developing countries.

key words: Ethical issues, dental research, biomedical research, developing countries.

INTRODUCTION: Debates on the ethical requirements for conducting medical and dental research in developing countries have reached in a considerable prominence in recent years. In developing countries, where cultural, linguistic, economic and other barriers may prevail between researchers and subjects ${ }^{1}$. Health research plays a pivotal role in addressing inequities in health and human development, but to achieve these objectives the research must be based on sound scientific and ethical principles. Although it is accepted that ethics play a central role in health research in developing countries, much of the recent debate has focused on controversies surrounding internationally sponsored research and has taken place largely without adequate participation of the developing countries. The relationship between ethical guidelines and regulations, and indigenously sponsored and public health research has not been adequately explored. In order to support health research in developing countries that is both 
relevant and meaningful, the focus must be on developing health research that promotes equity and on developing local capacity in bioethics. Only through such proactive measures can we address the emerging ethical dilemmas and challenges that globalization and the genomics revolution will bring in their wake ${ }^{2}$.

Good oral health is fundamental to good general health. Oral health research is therefore essential for improving health and wellbeing, and the dental research has been developed to accommodate all strands of clinical dental research, including quantitative and qualitative research, clinical trials and translational research. In the past few decades, the research and discoveries in the discipline of dentistry have been led to dramatic changes and paradigm shifts in terms of professional practice. New and enhanced research areas in dentistry include genomics, bone biology, forensics, implantology, community health, and applied clinical materials. For a number of years, bioengineers have been miniaturizing labs on a chip and discovering many modern dental equipments.

Individuals or communities in developing countries assume the risks of research, but most of the benefits may accrue to people in developed countries ${ }^{3}$. Although poverty, limited health-care services, illiteracy, cultural differences, and limited understanding of the nature of scientific research neither cause nor are necessary for exploitation, they increase the possibility of such exploitation ${ }^{4}$. Thus, a growing commercialization of research and its effects on the ethical conduct of researchers and the advancement of scientific knowledge are of concern today and need serious thought.

The misconduct in research and publication affects authors, reviewers and editors. Recently, there has been considerable debate raised about the ethical conduct and reviewing of health research, but this debate has largely taken place among ethicists and researchers in industrialized countries. The views of public health practitioners and researchers from developing countries have been underrepresented. ${ }^{5}$ Research investigators have an ethical obligation to conduct their research honestly through the judicious use of grant and contract funds for the purposes intended; accuracy in fully disclosing all research strategies, methods, results and analyses; and generous and accurate citation of other investigators' preceding or competing work ${ }^{6}$.

In developing country maximum researches are participatory that allows to the community and researcher to collaborate on research process and the development of knowledge that is beneficial to the community. This is due in part to the three main principles of participatory research that include collaboration, mutual education, and acting on results from research questions. The results of this type of research are adaptable and thus applicable to other communities ${ }^{7}$.

Advancement of dental research and implication of research ethics: A good deal of pioneering research has been carried out in gene therapy, stem cell research and regenerative medicine applied to oral health problems. Indeed, a recent editorial in the focused on the contentious issue of the potential research applications of human embryonic stem cells in tissue engineering and regenerative medicine. In future Scientists will discover the method for growing teeth from stem cells obtained in urine and stem cells sourced from dental pulp, ligament, and gum have previously been examined for tooth regeneration approaches. Although having particular advantages that human dental stem cells and may raise ethical issues. 
Dentistry of tomorrow will embrace the ability to restore form and function to parts of the oral cavity and craniofacial complex that have been damaged by either pathology or trauma using the regeneration techniques and reversal of the disease process being studied right now. Dentistry will have a whole new arsenal of opportunities and abilities to tackle devastating diseases and conditions that require restoration, as well as diagnostic and preventive measures. Between stem cells and tissue engineering, as well as gene therapy, dentists will be able to achieve what was previously impossible. In the future, emerging materials and techniques will allow the researcher to detect early signs of a carious lesion in a tooth and then, instead of actually drilling and filling, researcher will think about how to regrow enamel and dentin on that broken, researcher will able to use therapeutic medications to reverse the disease and stop it. The saliva research could lead to the salivary gland being used as a general bioreactor to replace proteins that are missing from an individual. For example, in the case of diabetes, gene therapy could be used to "trick" the salivary gland into producing insulin, if an individual lacked sufficient growth hormones, the salivary gland could be manipulated into producing what's needed.

In the last few decade many development by research dramatically changed the dentistry such as Invention of general and local anesthesia, Adhesive bonding, High-speed rotary instrumentation, digital radiography, computer aided design and computer aided manufacturing and Implant dentistry have created a revolution in the practice of dentistry. With fluoridated water and fluoride toothpastes in the 1950s and 1960s, the era of preventive dentistry began, leading subsequently to topical fluoride solutions, gels, and varnishes. The focus on the prevention of dental disease - not just the treatment of it—also led to increased interest in oral health education in hopes that preventive measures would have a positive impact on children's oral health. This is very significant and became important to the profession as well as for the public also. The introduction and later widespread use of toothpastes containing fluoride demonstrated that teeth could be retained caries-free for years.

In the past few decades, the research and discoveries within the discipline of dentistry have led to dramatic changes and paradigm shifts in terms of professional practice. Dentistry can credit such initiatives for its ahead role in health promotion, risk assessment, disease prevention, treatment planning, treatment therapeutics, restorative materials, and predictable clinical outcomes, among other achievements. Recently many dental Institutes is constantly looking for opportunities to borrow, enhance, and integrate knowledge from biomedical and technological research by using modern technology. To make any research involving human subjects or samples ethically acceptable, a number of key features have to be considered by the scientists. Those who conduct oral health research are compelled by regulations and convention to follow established ethical standards to protect human rights, regardless of where their research is conducted. As for most areas of research that come under ethical scrutiny, therefore, this research was done to observe the current ethical status in developing country giving special attention to dental research.

RESEARCH QUESTIONS: We addressed the following questions:

1) What are ethical issues arises in conducting research in developing country?

2) How we can minimize the conflict that raise during conducting dental research?

3) What are the things should be consider during conducting dental research in collaboration with others?

We systematically reported the relevant scientific information for each question. 


\section{OBJECTIVES:}

1. To examine the various ethical issues in research in developing country.

2. To gather information that will helpful for overcoming the ethical dilemma in research in developing country

3. To identify success factors for conducting the ethical dental research

4. To develop an ethical framework for research in developing country.

MATERIALS AND METHODS: In this review was done during the educational activity of National Institutes of Health Bethesda, Maryland held by Bangladesh Bioethics Society through video conferencing on September 25, 2013 through November 11, 2013. We performed the systematic literature search, screening process, rating of the evidence, assessment of the evidence and presentation of the contents of the evidence to the reader through the literature searched existing published and unpublished articles and reports that related to our topics of interest. In addition, web searches were conducted to get a general understanding of trends in these areas and to seek out further documents and potential key informants. Along with google and yahoo search we also used database including MEDLINE, PUBMED, HINARI etc .A total of 40 articles were retrieved and 17 of them were selected for review. . All protocols between 1990 to 2013 were cited by applying the key words; Ethical issues, dental research, biomedical research, developing countries. Papers only published in English were included in this review. Multiple reports from the same study only contributed once to the review.

Inclusion and exclusion criteria of article: Studies reported any ethical issues in relation with dental research in developing country were eligible for inclusion, additionally due to unavailability of related article, study with research ethics in developing country also were included. However, abstracts in conference programs with lack of essential information are excluded from this study.

RETRIEVED INFORMATION AND DISCUSSION: In recent years, controversies have arrived concerning the ethics of biomedical research sponsored by wealthy nations and conducted in resource poor countries. Individuals or communities in developing countries assume the risks of research, but most of the benefits may accrue to people in developed countries In order to support health research in developing countries that is both relevant and meaningful, the focus must be on developing health research that promotes equity and on developing local capacity in bioethics

A A Hyder et al $^{8}$ conducted a study on ethical review of health research; a perspective from developing country. In their study forty four percent of the survey respondents reported that their studies did not undergo any review (technical, scientific, or ethical) by a Ministry of Health in the developing country where the research was conducted. Twenty five percent of the respondents also reported that their studies did not undergo an ethics review by an IRB, ethics board, or Ministry of Health in the country. Further analyses showed that $15 \%$ of the studies being described in the survey were neither reviewed by the Ministry of Health nor by any ethics board in the developing country, of which one third were US funded. Of those studies funded by US sources, $12 \%$ were not reviewed by the country's own Ministry or Department of Health or an ethics board, while $17 \%$ of the non-US funded studies did not get any such review. 
The researchers were also asked to indicate which issues were raised by their IRBs. Developing country IRBs were most concerned about cultural appropriateness of the studies (59\%), need for local language consent form (58\%), relevance of research question to country where research was conducted $(54 \%)$, and the availability of intervention to host country after study was over (54\%). Researchers were also asked to report on their experiences with US IRB reviews. US IRBs were more likely to raise issues regarding, need for local language consent forms (84\%), need for letters of approval from developing country representatives (79\%), and complexity of the consent form (64\%). They concluded that researchers in the developing world have valuable experience with international and local ethical reviews, which contribute to global thinking on these. The researchers have reported that the review process generally happens and the proportion for US funded studies is not significantly different from non-US funded studies; however, there are gaps in the review process, which can result in a number of research projects not being reviewed. Therefore, the capacity to conduct ethical review in developing countries needs to be developed or enhanced.

Zulfiqar Ahmed Bhutta ${ }^{9}$ in his study on ethics in international health research; a perspective from the developing world concluded that in developing country strength in ethical review is insufficient and should be developed by strengthening models for reviewing the ethics of research, Ethics in international health research undertaking research must include the capacity to undertake ethical review of the planned research and its conduct. Local capacity could also be strengthened by developing partnerships, although international and regional networks or partnerships in bioethics are no substitute for local action. A review of the existing capacity in bioethics and in ethical review of research in developing countries reveals major gaps. Bioethics training must be strengthened in undergraduate medical education, and in postgraduate and public health training programmes. This will require a major investment in manpower and a new approach to the teaching of bioethics. The immediate need, however, is to strengthen local capacity and manpower by developing innovative training models for ethics that are cost-effective and sustainable. The opportunities afforded by the Internet for learning and education in ethics should also be utilized.

Michael et $\mathrm{al}^{10}$ have seen that there are indeed many ethical issues to be considered with reference to clinical trials taking place in developing countries. The difficulty of applying Western ideals on poor societies with different cultural and educational status is evident. And, sometimes, motivations of profit can make the sponsors behave in a rather unethical, or even unlawful and violent way. However, it needs to be kept in mind that these negative practices do not take place very often, and that clinical trials are usually conducted on the basis of the widely accepted international principles of ethical research. Developing countries have much to gain from Western sponsors, and international bodies recommend the development of more research programs for these areas. Priority should be given to training local health care professionals in ethical principles, and to organizing effective research ethics committees in order to supervise the procedures. Progress may be slow, but, in the long run, clinical trials have the potential to contribute significantly to the improving of health status in developing parts of the world.

In an article Benjamin Caballero ${ }^{11}$ recommended to give efforts to strengthen the application of ethical principles in research should focus on the underlying conditions that make it difficult to achieve a sustainable ethical climate in less-developed countries. Some of the tasks that should be considered as priorities include training in research ethics as part of the science curriculum at the undergraduate and graduate levels, support for capacity building in research ethics, and community involvement. 
G.R. Gillett ${ }^{12}$ stated in his article, in all contemporary medical research, there is an inherent conflict between the ethical requirement that we share information which will help those who are suffering and the need to preserve rights to competitively sensitive information related to product development and academic funding. These various pressures on research emphasize the need for an active and lively appreciation of ethical issues in contemporary biomedical sciences. The relevant information required for informed consent varies from situation to situation but should take into account the need for participants to make a reasoned decision about their involvement. Where community research is involved, there should be consultation with appropriate representatives

Benatar et $\mathrm{al}^{13}$ described that when those in privileged positions and in wealthier countries consider undertaking collaborative research with colleagues in developing countries it is necessary to understand both their own framework of thinking, and the implications of very different mind-sets and environments in which research projects may be carried out in developing countries. The mind set of researchers from industrialized countries, and in which the debates on research ethics are taking place, is characterized by a biomedical approach to disease, and by a neoliberal approach to economics and trade. These powerful forces shape the world and a dominant worldview. There is a need to be sensitive to the fact that not all, and especially not those who are disadvantaged or who have been exploited, will see the world through the same lenses.

Md. Fakruddin et $\mathrm{al}^{14}$ in their study described the perspective in research ethics in Bangladesh. In any clinical research it is essential to maintain an ethical guideline but unfortunately no such guideline is still formulated in Bangladesh. Every research organization should have an ethical review committee comprised of qualified ethical reviewer, but unfortunately except icddr,b, no organization have ethical review committee. Bangladesh Medical Research Council is mandated by Govt. to monitor and maintain the quality and ethical status of clinical research, its activity is not satisfactory till now. Again, most of the clinical researcher and other researchers are not aware of the importance of ethical clearance of their research. As a result, they face difficulty in publishing scientific article is reputed and international journals. Again, due to lack of ethical guidelines, participants or volunteers do not get back the feedback of the research. It is high time that the country formulate a national guideline on ethics for Biomedical and Clinical Research involving human participants or involving samples from human such as blood. Involved scientists and workers as well as common peoples should be aware of the applicability of the guideline

A study conducted in Brazil by Dalton et $\mathrm{al}^{15}$ and have shown that many advances in ethical issues have been made in the developing country. The dental community has adhered to and complied with the parameters of the ethical regulations. An effort has been made by dental researchers to obtain free and informed consent by research subjects, and greater care has been taken. Dental research in Brazil has been conducted in teaching and research institutions, often in the form of activities connected with graduate programs supported by funds from these institutions or from funding agencies, all from the public sector. The interests of sponsors should also be harmonized with those of society in connection with the use of public equipment, particularly when the research entails using research facilities or personnel trained and/or funded by public institutions. This same consideration should be borne in mind when the research involves both public health care institutions and those assisted by them, causing the study to ultimately make use of already limited public healthcare resources. Additionally, one must consider the issues relating to the transfer of technology. In this sense, two major fronts should be considered. One refers to a set of 
actions aiming at strengthening the ethical appreciation system; another important front is to guarantee the transparency of the whole research development process.

Frankel, M. $\mathrm{S}^{16}$ in his article Ethics in Research; Current Issues for Dental Researchers and Their Professional Society showed that the values associated with scientific investigations affect the conduct, evaluation, and reporting of research and lead to ethical issues for scientists engaged in dental research. This essay examines the relationship between scientists and the larger society in which they work, and how that relationship defines the boundaries of scientific freedom and autonomy, on the one hand, and scientific responsibility and accountability, on the other. Values underlie disputes over data sharing, perceptions of conflict of interest, and scientists' commitment to research integrity.

MJ et al ${ }^{17}$ conducted a survey of Ethical Issues in Dental Research. They showed that the overall, respondents rated practices that undermine the trustworthiness of science (falsifying or fabrication of research data, retaliation, failure to present negative results, failure to disclose involvement with commercial enterprises, failure to maintain research records, etc.) as more serious, but less prevalent, than practices considered disrespectful of the work of others (gift authorship, citing sources without reading them, dividing a project into many small units, etc.). All respondents said that they had observed each of the less serious problematic practices one or more times, whereas $10 \%$ reported having observed retaliation, $30 \%$ reported having observed falsification, and $54 \%$ reported having observed plagiarism one or more times. They concluded that status and years of experience are associated with more frequent observations of misconduct.

CONCLUSION: The actions required to move ahead in this field include strengthening bioethics capacity in developing countries; linking health research to community needs in a transparent and participatory process; and increasing communication between scientists and ethicists in industrialized and developing countries. The clear goal in all these activities must be the reduction of global inequities in health. This may take time, but it is the only way to bring about true change in the ethics of international health research, instead of having a superficial debate on the language of regulations. All guidelines are provided by the experts are internationally accepted and without following these guidelines, no clinical research is acceptable in the world. Though, there are many countries in the world which don't have any ethical guidelines of their own and thus scientists in those countries do not adhere the any ethical guideline while conducting their research. Each country should have their own ethical guidelines and each clinical research institutes should have own ethical review committee to ensure ethical clinical research.

RECOMMENDATION: Research ethics committees or institutional ethical review committees (ERCs) is to ensure that studies involving human research participants are designed to conform the relevant ethical standards and that the rights and welfare of participants are protected.

Ethics committees must be an independent research organization and should not function under the influence of others. Methodical review should ensures that studies have a favorable balance of potential benefits and risks, and that the participants are selected equitably, and that procedures for obtaining informed consent are adequate 
The research plan must receive prior review by an independent ethics review committee. The research must involve a reasonable risk-benefit ratio and efforts must be made to minimize the risk to research participants. Adequate plans for the care and compensation of participants for injuries directly related to the research must be presented. All participants must receive equal consideration and care. Individual informed consent must be obtained from all participants.

Bangladesh Medical Research Council (BMRC), the focal point for health research in the country has to play pioneer role to review the ethical aspects of a research project by 'National Research Ethics Committee'. The National Institute of Preventive and Social Medicine (NIPSOM), all the government medical colleges and different specialized government \& private health institutes have to patronize their own ethical review committees (ERCs).

\section{REFERENCES:}

1. Marshall P.A. The relevance of culture for informed consent in US funded international health research. Consultation Report for the President's National Bioethics Advisory Commission. 2001; Vol 11.

2. Zulfiqar Ahmed Bhutta, Ethics in international health research: a perspective from the developing world, Department of Paediatrics, The Aga Khan University, Karachi, Pakistan. Bulletin of the World Health Organisation (Impact Factor: 5.25). 02/2002; 80(2):114-20. Source: PubMed

3. Benatar SR. Avoiding exploitation in clinical research. Camb Q Healthc Ethics 2000; 9:562-5.

4. Glantz LH, Annas GJ, Grodin MA, Mariner WK. Research in developing countries: taking "benefit" seriously. Hastings Cent Rep 1998; 28:38-42.

5. Zulfiqar Ahmed Bhutta,Ethics in international health research: a perspective from the developing world, Bulletin of the World Health Organization 2002;80:114-120

6. Richard P. Ellen, DDS; Richard Singleton, Human Rights and Ethical Considerations in Oral Health Research, JCDA • www.cda-adc.ca/jcda • June 2008, Vol. 74, No. 5

7. Macauley, A. C., Commanda, L. E., Freeman, W. L., Gibson, N., McCabe M. L., Robbins, C. M., et al. Participatory research maximizes community and lay involvement. British Medical Journal 1999; 319, 774778

8. AA Hyder, S A Wali, A N Khan, et al. Ethical review of health research: a perspective from developing country researchers, J Med Ethics 2004 30: 68-72

9. Zulfiqar Ahmed Bhutta. Ethics in international health research: a perspective from the developing world. Bulletin of the World Health Organization (Impact Factor: 5.25). 02/2002; 80(2):114-20

10. Michael Igoumenidis1, Sophia Zyga Healthcare Research in Developing Countries: Ethical Issues health science journal. 2011; vol 5, issue 4.

11. Benjamin Caballero, Ethical issues for collaborative research in developing countries, Am $\mathrm{J}$ Clin Nutr October 2002, vol. 76 no. 4 717-720.

12. G. R. Gillett, Informed consent and moral integrity, Journal of Medical Ethics.1989; 15 (3):117-123.

13. S R benatar Lee \& Zwi, Reflections and recommendations on research ethics in developing countries, Social Science \& Medicine 54 (2002) 1131-1141 
14. Md. Fakruddin, Abhijit Chowdhury, Md. Nur Hossain, Khanjada Shahnewaj Bin Mannan, Ethics in clinical research, Bangladesh Journal of Bioethics 2012; 3(3):16-20

15. Dalton Luiz de Paula Ramos Development of dental clinical research in Brazil - a few (new) ethical challenges, Braz. oral res. vol.25 no.5 São Paulo Sept./Oct. 2011

16. Frankel, M. S. Ethics in Research: Current Issues for Dental Researchers and Their Professional Society Journal of Dental Research . Nov1994, Vol. 73 Issue 11, p1759-1765. 7p.

17. Bebeau MJ, Davis EL, Survey of ethical issues in dental research. J Dent Res. 1996 Feb; 75(2):845-55. 